\title{
Primary Coronary Angioplasty in a Nonagenarian
}

\author{
Luiano M Baradidi, Carlos V. Serrano Jr, Antônio Esteves, Jean Pierre Gporkin, José Carlos Nicalau
}

\author{
São Paulo, SP - Brazil
}

\begin{abstract}
A woman aged 98 years entered the tertiary hospital service with a picture of acute myocardial infarction of the extensive anterior wall, which began 4 hours earlier. Due to the large myocardial risk area suggested by the electrocardiogram, the patient was taken to the hemodynamics laboratory for the performance of emergency coronary arteriography, which revealed occlusion in the proximal third of the anterior descending artery. Primary angioplasty followed by stent grafting was successfully performed. The patient had a satisfactory evolution (Killip I) and was discharged from the hospital on the seventh postinfarction day. We discuss here aspects of thrombolysis and coronary percutaneous interventions in the aged.
\end{abstract}

Advanced age represents an important predictor of mortality during acute myocardial infarction, reaching $20 \%$ $30 \%$ of the intrahospital mortality index of patients aged above 70 years ${ }^{1}$. Lower rates of performance of thrombolytic and invasive procedures like coronary arteriography and angioplasty and higher indexes of complications like cardiac failure and death; are observed in this subgroup of patients ${ }^{1}$.

On the other hand, during the handling of acute myocardial infarction patients, primary coronary angioplasty is considered an effective procedure for revascularization the responsible artery and demonstrating a low incidence of hemorrhagic complications and improved ventricle function as well ${ }^{1,2}$.

It is the objective of this report to describe the performance of a primary coronary angioplasty in a 98-year-old patient.

\section{Case report}

The patient was a 98-year-old woman with a history of 4 years of infra-mandible pain brought on by minimal effort,

Instituto do Coração do Hospital das Clínicas - FMUSP

Mailing Address: Luciano M. Baracioli - InCor - Unidade Clínica de Coronariopatia Aguda - Av. Enéas de Aguiar - 05403-000 - São Paulo, SP - Brazil E-mail: cobaracioli@incor.usp.br lasting from 5 to 15 minutes, stopping spontaneously upon rest. The existence of diabetes mellitus, the smoking habit, systemic arterial hypertension, and dyslipidemia as risk factors for coronariopathy was denied by the patient, who was using nitrate, dioxin, furosemide, and diltiazem due to cardiopathy (sic). She was admitted to the Emergency Unit due to a complaint of typical high-intensity precordial pain irradiating to the left upper limb and mandible, already of 4hours duration. On clinical examination, she was mentally lucid, arterial pressure was $180 \times 100 \mathrm{mmHg}$, pulse was 60 bpm, she had a regular cardiac rhythm with a weak systolic murmur $++/ 4+$ in the mitral focus, and discrete crepitant stertor in the right base. The electrocardiogram revealed upper unleveling of the ST segment in the anterior and high lateral wall (DI, aVL, and V1-V5, Figure 1); thoracic radiography showed a pattern of discrete pulmonary congestion. Use of oral aspirin and intravenous nitroglycerin was begun; due to the high risk of fibrinolysis and the high lethality of acute myocardial infarction in this situation, the patient was taken to the hemodynamics room. On coronary arteriography, the descending anterior artery was shown to be occluded in its proximal third and the right coronary artery obstructed in $80 \%$ of its medial third. Left ventriculography showed anterior-apical akinesia. The patient underwent mechanical revascularization of the anterior descending artery by percutaneous transluminal angioplasty followed by stent grafting (Figure 2).

Following the procedure, the patient was taken to the Coronary Unit, where she experienced good evolution (Killip I). Laboratory findings showed an enzyme curve peaking at 12 hours with $285 \mathrm{IU} / \mathrm{L}$ (normal up to $10 \mathrm{IU} / \mathrm{L}$ ) (Figure 3). The bi-dimensional echocardiogram performed on the second postinfarction day showed apical anterior-septal akinesia, anterior hypokinesia, and calcification of the mitral ring with discrete insufficiency; results were not different from those shown on the next examination taken on the $5^{\text {th }}$ postinfarction day. The patient remained using aspirin, ticlopidine, an angiotensin-converting enzyme inhibitor, and a beta-blocker, which was soon stopped due to significant bradycardia. The patient was discharged from the hospital on the $7^{\text {th }}$ postinfarction day, with this medication. 


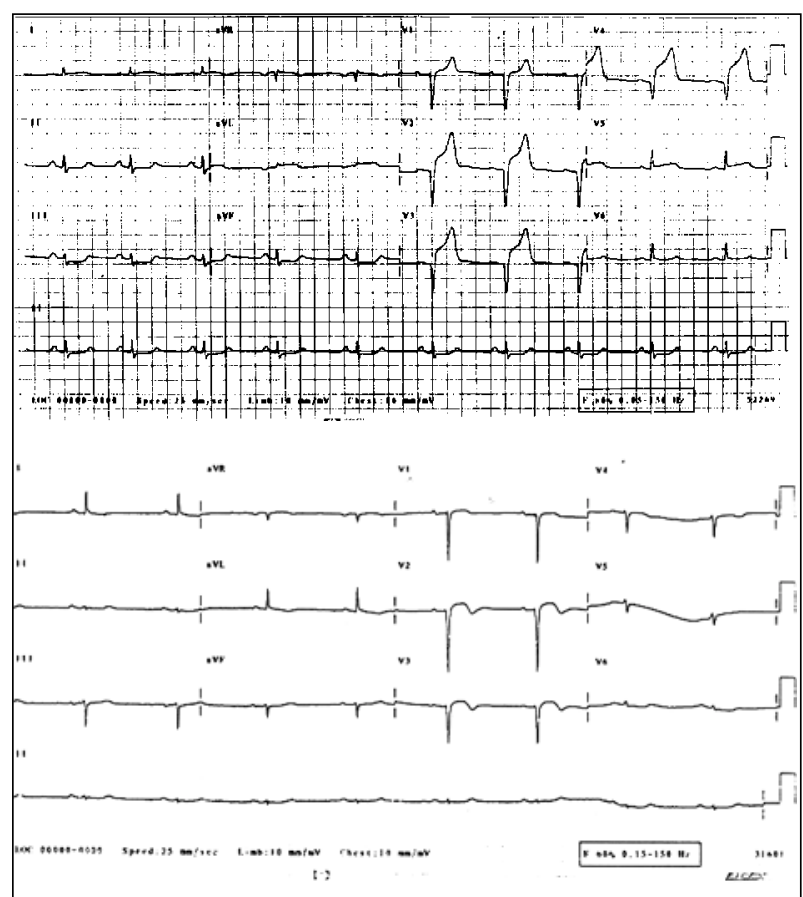

Fig. 1 - Electrocardiographic evolution. (1A) Electrocardiogram at admission: upper unleveling of segment ST in derivation $\mathrm{DI}, \mathrm{aVL}$, and V1-V5: Q wave in derivations V1V4; infraunleveling of segment ST in derivations DII, DIII, and aVF-characterizing acute myocardial infarction at the anterior wall; (1B) electrocardiogram on the $5^{\text {th }}$ postinfarction day; alteration of ventricle repolarization at derivations $\mathrm{DI}, \mathrm{aVL}$, and VI-V5, and decreased R waves at derivations DII, DIII, and the aVF.

\section{Discussion}

Due to various factors, the average age of the population is increasing significantly; the higher rate of growth occurs in patients over 65 years of age ${ }^{3}$. According to some estimates, the number of the quite aged (over 85 years) will increase from 3 to 4 times until 2003, while the increase in the younger population will be smaller. These aged populations will consume a higher amount of resources in healthcare, cardiovascular disease being the major overall cause of mortality and morbidity in the aged ${ }^{3}$.

The relation between age and coronary artery disease has been well recognized since the classical study by White et al in $1990^{4}$, who showed that more than $50 \%$ of patients over 50 years of age had a coronary lesion in at least 1 vessel. The tendency is for these lesions to increase simultaneously with aging, probably due to the accumulation of and long exposure to risk factors.

An important fact to be remembered is the relationship between sex, coronary disease, and age. For instance, in young individuals (up to 35 years of age), the ratio of events between men and women is 5:1; in the aged ( $>75$ years) a relative increase occurs in the number of events among females, bringing this ratio to $1: 1^{5}$.

The diagnosis of acute myocardial infarction is made in accordance with the definition of the World Health Organization ${ }^{6}$, independently of the patient's age. It is based on the presence of at least 2 of the 3 following criteria: (1) a clinical history of precordial pain of an ischemic character, (2)

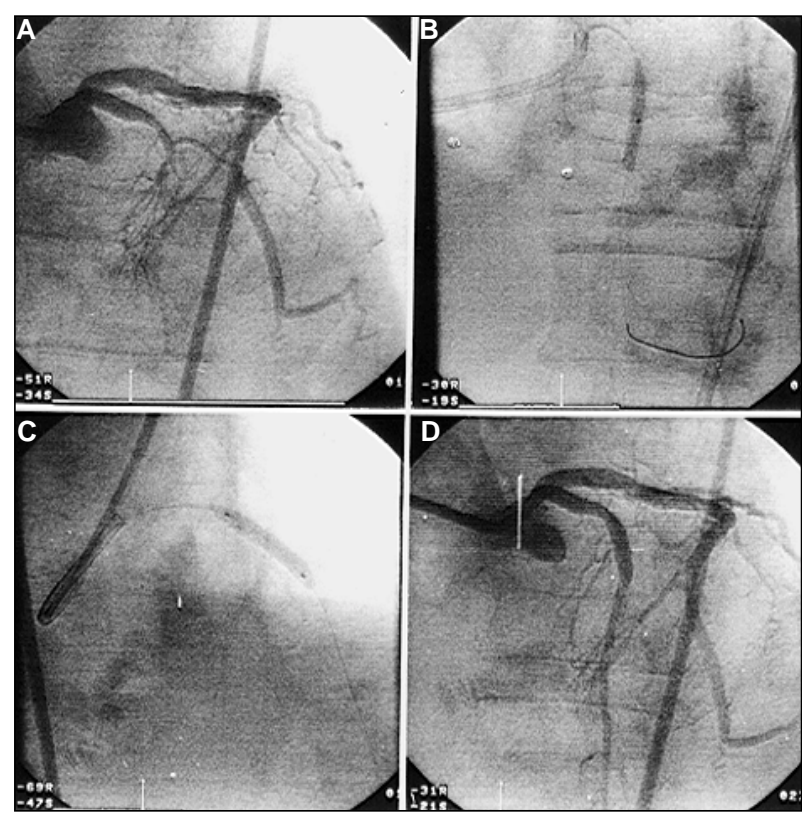

Fig. 2-Coronary arteriography. (2A) posterior-anterior image showing evidence of occlusion in the proximal third of the anterior descending artery; (2B) in the oblique left anterior (cranial) image, the passing of the guidance thread through the lesion and balloon insuflation; (2C) in the oblique right anterior image, the intracoronary grafting of the stent (IRIS II); (2D) the posterior-anterior (cranial) image demonstrates the final result of the mechanical revascularization procedure.

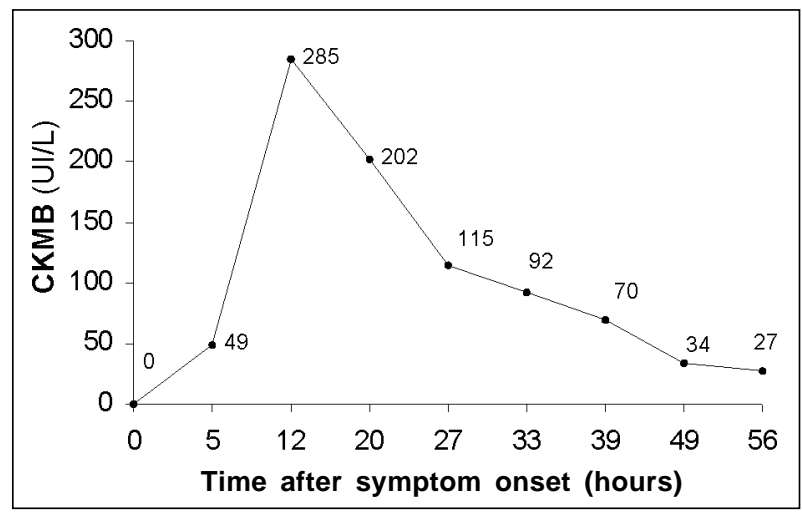

Fig. 3 - Phospho creatine MB fraction (CKMB) levels.

serial electrocardiogram alterations, and (3) curves of serum cardiac (enzyme) markers. In the aged, attention should be paid to the presence of equivalent ischemic symptoms: isolated dyspnea in $20 \%-30 \%$, syncope in $10 \%$, mental confusion in $10 \%$, and signs or symptoms of cerebrovascular accident in $1-2 \%{ }^{3}$.

It is, however, important to point out that in women over 85 years of age, myocardial infarction fails to be clinically recognized in about $50 \%$ of cases, being noted only after electrocardiogram findings ${ }^{5,7}$.

It is known that in acute myocardial infarction, advanced age is not only an independent risk factor for cerebral hemorrhage, but also an independent mortality risk. Yet, the risk of bleeding should also be evaluated, taking into account the potential benefit of the use of medication in this age group. 
The Fibrinolytic Therapy Trialists' Overview ${ }^{8}$, a randomized metaanalysis including the study of more than 1,000 patients suspected of having acute myocardial infarction, demonstrated that the highest benefit for fibrinolytic therapy in saving lives occurred in the group of patients aged over 75 years. Intrahospital mortality was higher in the aged population, but with a great reduction in those given thrombolytic therapy $(22.1 \%$ mortality in placebo-treated aged patients versus $17.9 \%$ in those given thrombolytics). More recently, Thiemann et al ${ }^{9}$ following a retrospective analysis for thrombolytic therapy of 7,864 acute myocardial infarction patients aged between 65 and 86 years, concluded that: (a) in those between 65 and 75 years, fibrinolytic therapy promoted a survival benefit in 30 days; (b) in those over 75 years of age, fibrinolytic therapy worsened survival time, with a ratio to 30 day mortality of $1.38 \%$ (95\% IC 1.12-1.71, P=0.003). In these patients, even when subgroups were analyzed, no benefits were obtained by the use of fibrinolytic drugs 9 .

Other important clinical variables, correlated to a higher risk of hemorrhage (mainly intracranial) and the use of thrombolytics, include besides age over 65 years, low body weight $(<70 \mathrm{~kg}$ ), arterial hypertension (systolic arterial pressure $>180 \mathrm{mmHg}$ ) at the moment of presentation, and the use of $\mathrm{r}$-tPa as a thrombolytic ${ }^{6}$. The GISSI - 2 and ISIS - 3 demonstrated that the incidence of intracranial hemorrhage was higher in patients who received r-tPA, relative to those who received streptokinase. In the Global Utilization of Streptokinase and t-PA for Occluded Coronary Arteries (GUSTO)-I study ${ }^{10}$, the incidence of intracranial hemorrhage was $2.1 \%$ in patients aged over 75 years who used r-tPA and $1.2 \%$ in patients of the same age group as those who used streptokinase.

According to the directions for acute myocardial infarction recently published by the ACC and AHA ${ }^{11}$, the indication for a thrombolytic drug in patients $\geq 75$ years of age is class IIa, meaning that conflicting opinions exist about it, but with greater evidence in its favor.

Primary angioplasty in acute myocardial infarction, without previous use of a thrombolytic drug, has been shown to be comparatively efficient in the revascularization of the "guilty" vessel. Analysis of 3 large randomized studies 12-14 comparing thrombolytic therapy with primary angioplasty, suggests advantages relative to mortality, intrahospital infarction, and morbidity, favoring the group of invasive measures. In the Primary Angioplasty in Myocardial Infarction (PAMI) study ${ }^{12}$, among 395 infarction patents, 150 $(38 \%)$ were over 65 years. In these, a $6 \%$ mortality rate occurred in the group that underwent primary angioplasty and $15 \%$ for the group treated with thrombolytics, with a $0 \%$ and $6 \%$ incidence of cerebrovascular accidents, respectively. Mattos et al ${ }^{15}$, in a national experiment, evaluated the results of primary coronary angioplasty in 42 patients aged over 70 years; $86 \%$ of the cases were successful, no hemorrhagic complications occurred and hospital mortality was $14.2 \%$. In a larger study, the investigators of GUSTO $\mathrm{IIb}^{16}$ $(1,138$ patients with acute myocardial infarction randomized for primary angioplasty or accelerated r-tPA) suggest that the invasive procedure has a small to moderate advantage in the short run, but that this gain was not observed after a 6month evolution, when the primary common objectives (death, reinfarction, cerebrovascular accident) were analyzed. At present, we await the conclusion of Seniors PAMI trial, a randomized study currently in the patient screening phase comparing strategies of primary angioplasty with stent grafting and the use of abciximab versus thrombolysis in acute myocardial infarction patients aged over 75 years.

According to the directions for acute myocardial infarction of the Brazilian Society of Cardiology, primary angioplasty is indicated as of class A: (1) as an alternative to fibrinolytic therapy, provided it can be performed in the hospital, within at most a delay of 90 minutes, by experienced technicians; (2) in patients where fibrinolytic use is contraindicated. As a B1 indication, patients with a clinical/radiological picture of left ventricle dysfunction are included.

In summary, the present case report points out that acute myocardial infarction in the aged has a high morbidity-mortality index, and that fibrinolytic therapy involves risks that must be analyzed relative to benefits. The use of primary angioplasty is emphasized: it can be performed with good results even in patients of very advanced age, as in the situation here reported.

\section{References}

1. Lee TC, Laramee LA, Rutherford BD, et al. Emergency percutaneous transluminal coronary angioplasty for acute myocardial infarction in patients 70 years of age and older. Am J Cardiol 1990; 66: 663-7.

2. Holmes DR Jr, Gersh BJ. The role of percutanous transluminal coronary angioplasty in acute myocardial infarction. In: Gersh BJ; Rahimtoola SH: Acute Myocardial Infarction. $2^{\text {nd }}$ edition. New York: 1997: 549-66.

3. Kitzman DW, O'Connor CM. Acute myocardial infarction in elderly. In: Gersh BJ, Rahimtoola SH. Acute Myocardial Infarction. $2^{\text {nd }}$ edition. New York: 1997: 602-34.

4. White NK, Edwards JE, Dry TJ. The relationship of the degree of coronary atherosclerosis with age, in men. Circulation 1950; 1: 1345-54.
5. Vokonas PS, Kannel WB. Epidemiology of coronary heart desease in the elderly. In: Tresch DD, Aronow WS. Cardiovascular Disease in the Elderly Patient. New York: Marcel Dekker Inc., 1994: 91-123.

6. Ryan, et al. Guidelines for the management of patients with acute myocardial infarction: a report of the American College of Cardiology/American Heart Association Task Force on Practice Guidelines. J Am Coll Cardiol 1996; 28: 1328-428.

7. Kannel WB, Abbot RD. Incidence and prognosis of unrecognized myocardial infarction: an update on the Framingham Study. N Engl J Med 1984; 311: 1144-52.

8. Fibrinolytic Therapy Trialists' (FTT) Collaborative Group. Indications for fibrinolytic therapy in suspected acute myocardial infarction: colaborative overview 
of early mortality and major morbidity results from all randomised trials of more than 1000 patients. Lancet 1994; 343: 311-22.

9. Thiemann DR, Coresh J, Schulman SP, Gerstenblith G, Oetgen WJ, Powe NR. Lack of benefit for intravenous thrombolysis in patients with myocardial infarction who are older than 75 years. Circulation 2000; 101: 2239-46.

10. The GUSTO Investigators: an international randomized trial comparing four thrombolytic strategies for acutemyocardial infarction. NEngl JMed 1993;329:673-82.

11. Ryan, et al. Guidelines for the management of the patients with acute myocardial infarction. A report of the American College of Cardiology/American Heart Association Task Force on Practice Guidelines. Circulation 1999; 100: 1016-30.

12. Grines CL, Browne KF, Marco J, et al. A comparison of immediate angioplasty with thrombolytic therapy for acute myocardial: the Primary Angioplasty in Myocardial Infarction Study Group. N Engl J Med 1993; 328: 673-9.
13. Zijlstra F, de Boer MJ, Hoorntje JC, et al. A comparison of immediate coronary angioplasty with intravenous streptokinase in acute myocardial infarction. $\mathrm{N}$ Engl J Med 1993; 328: 680-4.

14. Ribeiro EE, Silva LA, Carneiro R, et al. Randomized trial of direct coronary angioplasty versus intravenous estreptokinase in acute myocardial infarction. J Am Coll Cardiol 1993; 22: 376-80.

15. Mattos, LA, Cano MN, Maldonado G, et al. The use of primary coronary angioplasty in acute myocardial infarction in patients over 70 years of age. Arq Bras Cardiol 1992; 58: 181-7.

16. A clinical trial comparing primary coronary angioplasty with tissue plasminogen activator for acute myocardial infarction. The Global Use of Strategies to Open Occluded Coronary Arteries in Acute Coronary Syndromes (GUSTO IIb). Angioplasty Substudy Investigators. N Engl J Med 1997; 336: 1621-8. 